\title{
Construction of the Talent Training System of New Engineering Specialty in Engineering Education Certification
}

\author{
Jing Bai, Zhenxiong Zhou*, Tiecheng Pu, Hongxi Wang \\ College of electrical and information engineering, \\ Beihua University, Jilin, China
}

\begin{abstract}
The purpose of the work is to propose a talent training system of new engineering specialty integrated with the engineering education certification standards. Firstly the talent training system is constructed according to the establishment of training objectives, graduation requirements, curriculum knowledge system, engineering ability training system and the improvement of continuous improvement mechanisms based on the quality evaluation system. Then the automation, information and electrical specialties have practiced the proposed talent training system in the College of Electrical and Information Engineering of Beihua University. At last the disciplines have received connotative development.
\end{abstract}

Keywords-New engineering; Engineering education certification; Talent training system; Connotative development

\section{INTRODUCTION}

According to the statistics of World Federation of Engineering Organization (WFOE), the construction of engineering capacity and the environment has become a globally recognized priority development direction [1]. In the process of realizing the goal of engineering capacity-building in all countries of the world, the training, development and reserve of engineering and technical talent play a very important role.

In 2016, China formally joined the Washington Accord (WA) and became a full member. It brings opportunities and challenges to engineering education in China. On the one hand, the undergraduate degree of engineering education in China has been recognized by the member countries of the agreement; on the other hand, China must train talent in accordance with international standards [2].

For meeting the international standards, the Ministry of Education has officially launched the new engineering plan after the repeated discussions, investigations and demonstrations since 2017. The "Fudan Consensus", "Tianda Action" and "Beijing Guidelines" and other program documents have been formed [3-5]. Whether new or traditional engineering disciplines, the basic purpose of training talents is to meet the needs of new economic development. The key of

Key Teaching and Research Project of Jilin Provincial Education Department in 2019 "Research on constructing talents training system of new engineering specialties guided by engineering education Certification". Important Teaching and Research Project of Beihua University in 2017 "Research on talents training system of automation specialty in new engineering". training talents is the talent training system.

This paper researches the talent training objectives, graduation requirements, curriculum knowledge system, engineering ability training system and quality evaluation system based on the engineering education certification and new engineering construction. The proposed talent training system has been practiced in the automation, information and electrical specialties in the College of Electrical and Information Engineering of Beihua University.

\section{ENGINEERING EDUCATION CERTIFICATION}

The objectives of engineering education certification in China are [6]: First, to ensure the quality of engineering education and promote the reform of engineering education through the engineering education certification; Second, to lay a solid foundation of The certification and registration system for professional Engineers in China; Third, to strengthen the workLinks between the engineering education and the industry; Fourth, to promote the communication between China and international counterparts and to realize the substantive equivalence of the engineering education.

Guided by the Engineering education certification, an integrated talent training system for new engineering is proposed in order to ensure that the talent training always can meet the needs of economic development.

\section{A. The architecture}

The talent training system to be studied should meet the standard framework of engineering education certification shown in Fig. 1 [7]. It highlights the concept of "studentcentered" talent training.

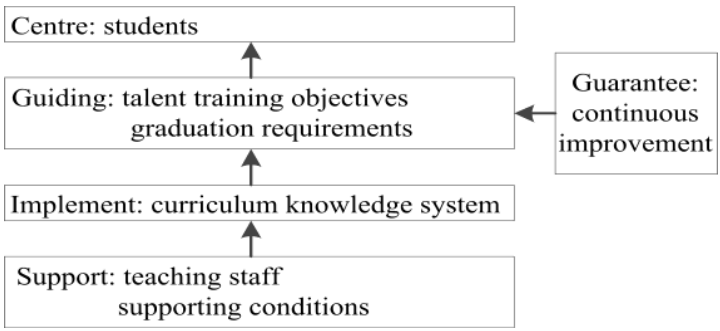

Fig. 1. The architecture of engineering education certification standards 


\section{B. Teaching Procedures design}

According to the engineering education certification standard, the teaching procedures should be designed by the concept of outcome-based education (OBE) shown in Fig.2. The internal and external circulations ensure the continuous renewal of the teaching procedures.

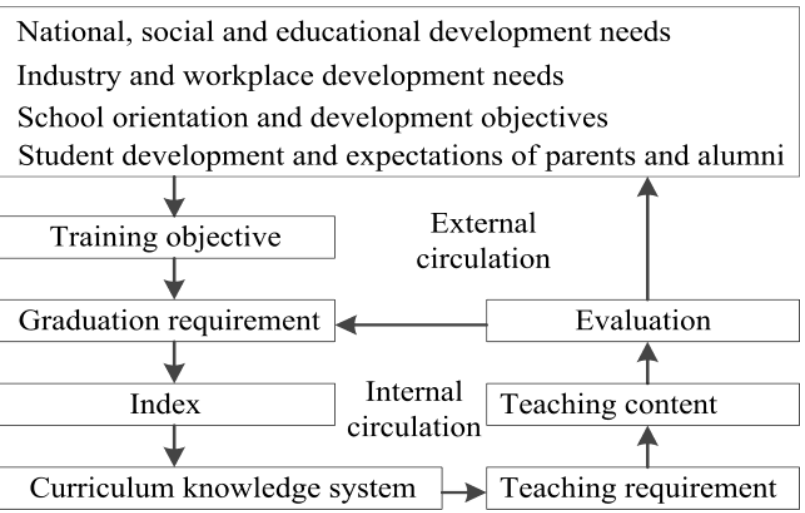

Fig. 2. Flow charting for outcome based education (OBE) teaching procedures

\section{TALENT TRAINING SYSTEM}

The specialty basic requirements are determined by the engineering education accreditation standard in China. The basic knowledge system of traditional specialty is transformed into the knowledge system of new engineering specialty according to the needs of the new industry of national strategy "Made in China 2025". Based on these, the curriculum knowledge system and engineering ability training system are established in turn. Then the teaching plan, course content and practical teaching content are determined. Finally, all the teaching implementation management and teaching quality assurance are completed through the teaching quality evaluation and monitoring system.

\section{A. Three Dimensionals Training Objectives}

Starting from the economic and social development in the new era and the needs of enterprises in new industries, and combining with the requirements of specialty certification of higher engineering education in China, the basic requirements for training new abilities of new engineering talents are analyzed. The training objectives of talents in new engineering specialty are determined, as shown in Fig. 3.

Socialist builders and successors of all-round development of moral, intellectual, physical, artistic

Quality and labor

\begin{tabular}{|ll|}
\hline Lifelong learning & Engineering thinking \\
Cooperative learning & Ethical thinking \\
Crossover collaboration & Global thinking \\
Integrated innovation & Internet thinking \\
\hline Engineering foundation & Speciality \\
Humanistic society & Mathematical \\
\hline
\end{tabular}

Ability

Knowledge

\section{B. Graduation Requirements}

The supportability of graduation requirements refers to the description of students' relevant abilities by specialty graduation requirements, which should reflect the support of the specialty training objectives. As shown in Fig.4, the graduation requirements covering 12 general standards should be formulated. At the same time, the characteristics of the new engineering specialty should be taken into account, and the graduation requirements indicators should be decomposed.

The graduation requirements formulated by the specialty should cover the contents of 12 graduation requirements in the standard in terms of breadth, and the students' abilities described should not be less than the basic requirements of the 12 standards to a certain extent.

1. engineering knowledge
2. problem analysis
3. design And development
4. research
5. use the tools
6. engineering and society
7. environment and development
8. business ethics
9. individual and team
10. communication
graduation
requirements
11. project management
12. lifelong learning

Fig. 4. Graduation requirements of trained talent

\section{Curriculum Knowledge System}

The curriculum knowledge system of new engineering specialties includes four curriculum modules as shown in Fig. 5 , i.e., the public curriculum module, the engineering basic curriculum module, the professional basic curriculum module and the professional curriculum module.

The public curriculum module includes mathematics, physics, English, sports, political theory, law, environmental protection, economic management and ethics, which fully meet the requirements of general courses for engineering education professional certification. Starting from the basic engineering curriculum module, the needs of new engineering are gradually considered, and engineering teaching is integrated into all specialties. The curriculum knowledge system with prominent specialty characteristics is established under the engineering education certification standard.

For example, with regard to the electrical engineering and automation specialty, the engineering basic course module contains the circuit theory, electronic technology, the electromagnetic theory and engineering graphics courses. The professional basic course model contains the electronics, the power system foundation and the power electronics technology courses. The professional curriculum module highlights the development needs of new industries, and the curriculum setting is less required by the engineering education

Fig. 3. Training objectives of the talent in new engineering specialty 
certification standard. The purpose is to improve the matching degree between the talent training and social needs.

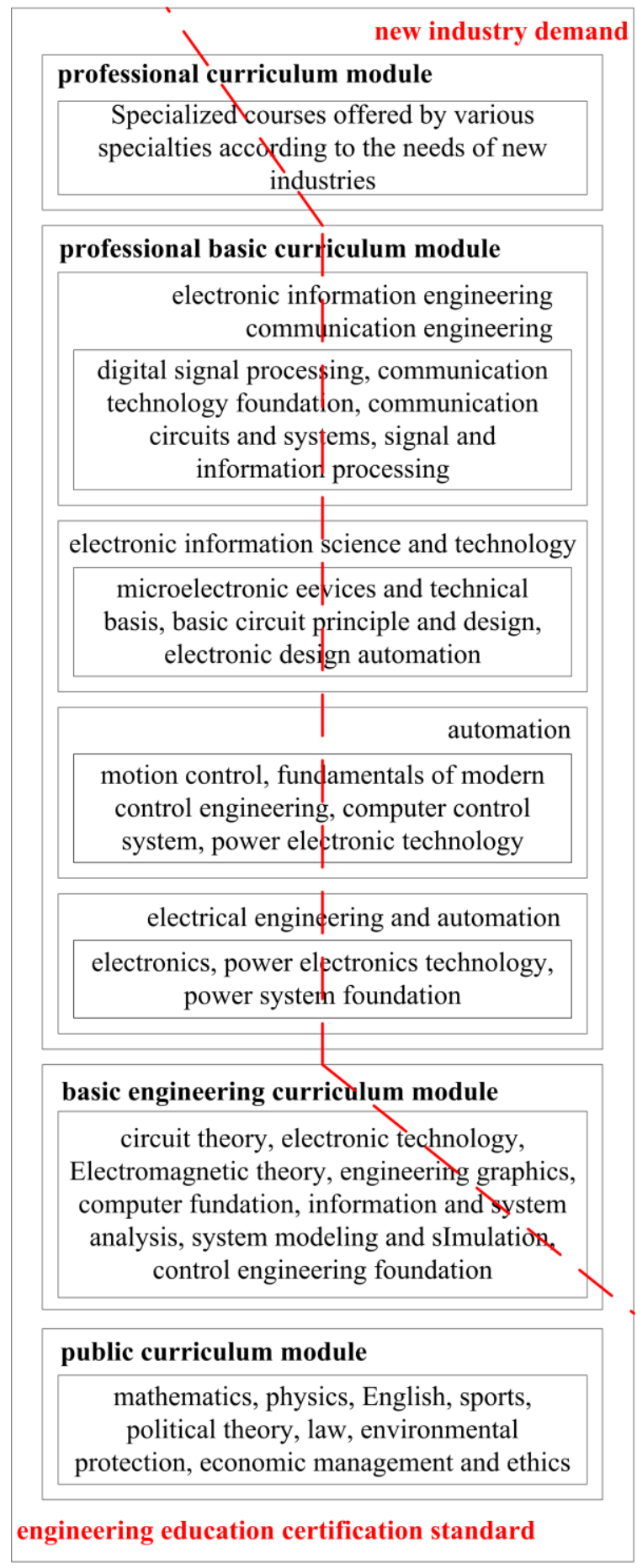

Fig. 5. Curriculum Knowledge System

\section{Engineering Ability Training System}

Based on the concept of engineering education certification, the training system of engineering ability is established, with the cultivation of students' ability to solve complex engineering problems as the core. As shown in Fig.6, it is divided into three levels and 12 types of practical training.

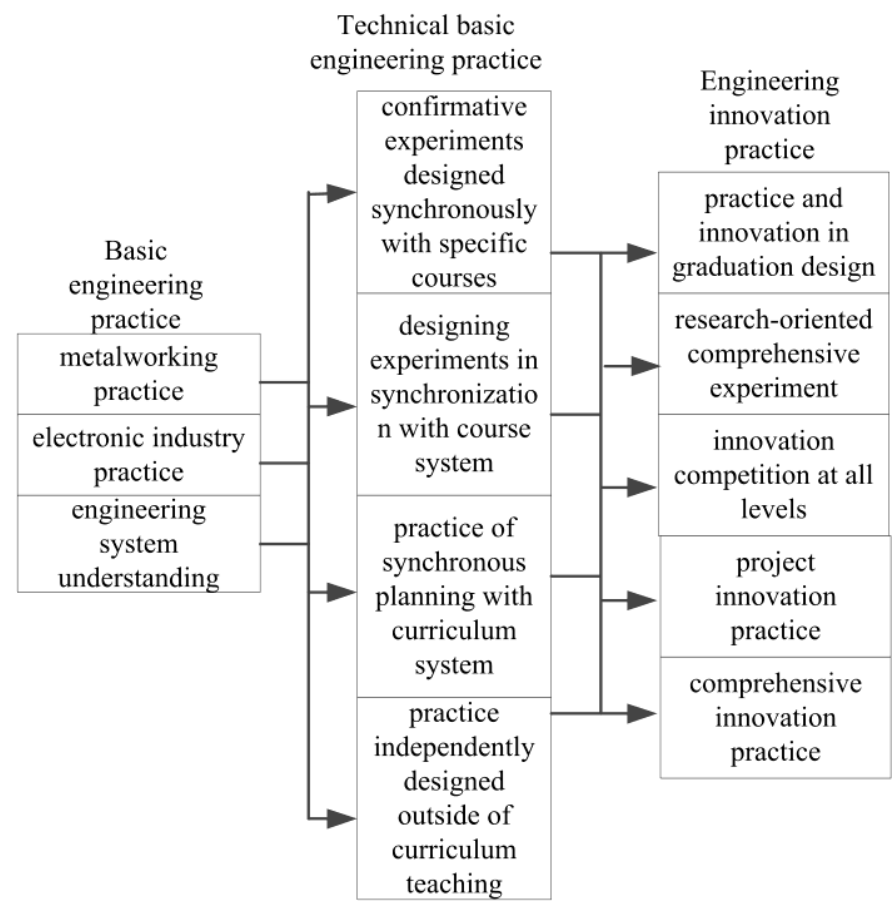

Fig. 6. Engineering Ability Training System

The basic engineering practice level mainly carries out metalworking practice, electronic industry practice and engineering system understanding. The technical basic engineering practice level takes the experiment, practice and practice as the main line. The verification experiments and design experiments are set up synchronously with specific courses. The practice of curriculum group corresponding to the synchronous planning of curriculum system is carried out. The practice is a practice designed independently outside the course teaching. This part of practice goes deep and the content of practice goes from simple to complex. The engineering innovation practice level includes practice and innovation in graduation design, scientific research-oriented comprehensive experiments, innovation competitions, project innovation practice and comprehensive innovation practice.

\section{E. Quality Evaluation and Monitoring System}

To develop higher education, the core task is to improve its quality. Quality assurance is the fundamental guarantee for the development of higher education, while curriculum is the core of teaching process, and curriculum quality is the cornerstone of specialty talent training quality.

Aiming at the problem of rigid and backward teaching management in the past, the teaching management system is improved combining with the teaching concept of "continuous improvement" of engineering education certification. Through student evaluation, peer evaluation and industry evaluation, an adaptive control system of "cascade+ three closed-loop+ feedforward" is formed to realize continuous improvement, selfrenewal and self-development based on the quality evaluation. The talent training objectives are consistent with the needs of local economic and social development. The established quality evaluation and monitoring system is shown in Fig.7. 


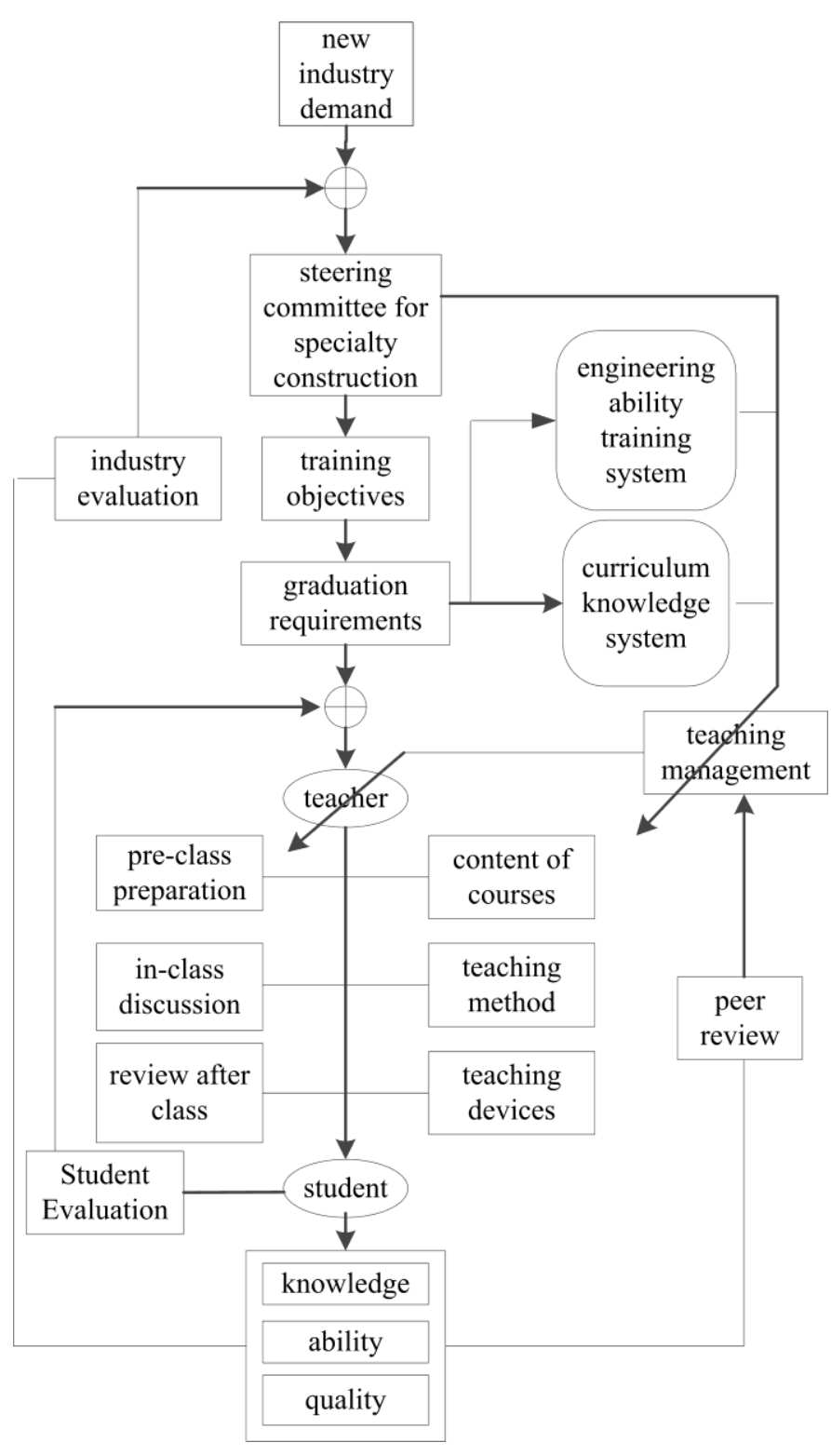

Fig. 7. Quality Evaluation and Monitoring System

\section{CONCLUSION}

In order to meet the needs of new engineering specialties in the strategic planning of "Made in China 2025", and in light of the actual situation of the five existing traditional specialties in in the College of Electrical and Information Engineering of Beihua University, which need to be reformed urgently and are all covered in the specialties of the new engineering, this paper takes the engineering education certification as the guide to construct an integrated talent training system of new engineering specialties that effectively integrate engineering education certification with the needs of new industries.

The talent training system includes the talent training objectives, graduation requirements, curriculum knowledge system, engineering ability training system and quality evaluation system. The talent training objectives are made by the economic and social development in the new era and the needs of enterprises in new industries. The graduation requirements cover the contents of 12 graduation requirements in the engineering education certification standard. The curriculum knowledge system consists of four modules, i.e., the public curriculum module, the engineering basic curriculum module, the professional basic curriculum module and the professional curriculum module. Each module is composed of different proportions of new subject content and engineering certification content according to its function. The engineering ability training system is divided into three levels and 12 types of practical training. The quality evaluation and monitoring system is implemented by the teaching concept of "continuous improvement" of engineering education certification.

\section{ACKNOWLEDGMENT}

Jing Bai, Zhenxiong Zhou, Tiecheng Pu and Hongxi Wang thank the anonymous reviewers for their careful work and thoughtful suggestions that have helped improve this paper substantially.

\section{REFERENCES}

[1] World Federation of Engineering Organization - Committee on Education in Engineering [EB/OL]. https://www.wfeo.org/committeeeducation-in-engineering/.

[2] International Engineering Alliance - Educational Accords - Washington Accord [R]. New Zealand, 2015: 4-16.

[3] "New engineering construction Fudan Consensus" Research in Higher Education of Engineering[J], 2017(1), pp. 10-11. (In Chinese)

[4] "New engineering construction path Tianda Action" Research in Higher Education of Engineering[J], 2017(2), pp. 24-25. (In Chinese)

[5] "New engineering construction guide Beijing Guideline" Research in Higher Education of Engineering[J], 2017(4), pp. 20-21. (In Chinese)

[6] H. F. Zhou, Z. W. Zhu, and M. G. Li, "Development and innovation of engineering education certification and its enlightenment to engineering education in China - summary of the 2016 international symposium on engineering education certification" University Teaching in China[J], 2017(1), pp. 88-95. (In Chinese)

[7] Y. Yorozu, M. Hirano, K. Oka, and Y. Tagawa, "Development of a graduate on-line certification program in engineering education" International Journal of Engineering Education[J], vol. 34, pp.1549-1561, 2018 